\title{
C/EBPa regulates SIRT1 expression during adipogenesis
}

\author{
Qihuang Jin ${ }^{1, *}$, Fang Zhang ${ }^{1,2, *}$, Tingting Yan $^{1,2}$, Zhen $\mathrm{Liu}^{1,2}$, Chunxi Wang ${ }^{1}$, Xinjian Ge ${ }^{1,2}$, Qiwei Zhai ${ }^{1,2}$ \\ ${ }^{1}$ Key Laboratory of Nutrition and Metabolism, Institute for Nutritional Sciences, Shanghai Institutes for Biological Sciences, Chi- \\ nese Academy of Sciences, Shanghai 200031, China; ${ }^{2}$ Graduate School of the Chinese Academy of Sciences, Shanghai 200031, \\ China
}

SIRT1 plays an important role in adipogenesis, but how SIRT1 is regulated in adipogenesis is largely unknown. In this study, we show that both SIRT1 protein and mRNA levels were increased along with CCAAT/enhancer-binding protein $\alpha(C / E B P \alpha)$ during adipocyte differentiation. C/EBP $\alpha$, but not C/EBPop30, activated SIRT1 promoter in both HeLa cells and 3T3-L1 preadipocytes. Furthermore, C/EBP $\alpha$ upregulated SIRT1 mRNA and protein levels in HeLa cells and increased SIRT1 expression in a p53-independent manner in Soas2 cells. In preadipocytes, ectopic expression of C/EBP $\alpha$ upregulated SIRT1 protein level and knockdown of C/EBP $\alpha$ led to the decrease of SIRT1 protein level. Moreover, by promoter deletion analysis, gel shift assay and chromatin immunoprecipitation, we found that $\mathrm{C} / \mathrm{EBP} \alpha$ bound to the SIRT1 promoter at a consensus C/EBP $\alpha$ binding site. These data demonstrate that $\mathrm{C} /$ EBP $\alpha$ regulates SIRT1 expression during adipogenesis by directly binding to the SIRT1 promoter.

Keywords: SIRT1, C/EBP $\alpha$, adipogenesis, transcriptional regulation, obesity

Cell Research (2010) 20:470-479. doi: 10.1038/cr.2010.24; published online 16 February 2010

\section{Introduction}

SIRT1 plays important roles in a wide variety of processes, including stress resistance, energy metabolism and differentiation [1]. In stress resistance, SIRT1 prevents apoptosis by regulating p53, Ku70 and FOXO family proteins [2-5]. In energy metabolism, SIRT1 regulates glucose homeostasis by regulating PGC- $1 \alpha$ transcriptional activity, insulin secretion and insulin sensitivity [6-9]. In cell differentiation, overexpression of SIRT1 was reported to prevent myogenesis in $\mathrm{C} 2 \mathrm{C} 12$ cells by regulating MyoD [10]. SIRT1 also retards adipogenesis in 3T3-L1 cells by inhibiting PPAR $\gamma$ (peroxisome proliferator-activated receptor $\gamma$ ) [11]. In differentiated 3T3-L1 adipocytes, upregulation of SIRT1 is shown to trigger lipolysis and loss of fat [11]. Thus, SIRT1 could be a potential pharmacological target for obesity and obesity-related diseases. It has been reported that resveratrol, a SIRT1 activator, renders the animals resistant

*These two authors contributed equally to this work.

Correspondence: Qiwei Zhai

Tel: + 86-21-5492-0903; Fax: + 86-21-5492-0291

E-mail: qwzhai@sibs.ac.cn

Received 07 July 2009; revised 13 October 2009; accepted 24 November 2009; published online 16 February 2010 to diet-induced obesity and insulin resistance $[9,12,13]$. Because of the important roles of SIRT1 in adipogenesis and lipid metabolism in adipocytes, understanding the mechanisms of regulation of SIRT1 expression during adipocyte differentiation will provide valuable information for therapy of obesity and obesity-related diseases.

Adipocyte differentiation is controlled by a series of cascades of transcription factors. CCAAT/enhancer-binding protein $(\mathrm{C} / \mathrm{EBP})$ family proteins are important components of the main cascade [14]. In this cascade, adipogenic inducers first stimulate the expression of $\mathrm{C} / \mathrm{EBP} \beta$ and $\mathrm{C} / \mathrm{EBP} \delta$, which facilitate the expression of PPAR $\gamma$, and PPAR $\gamma$ along with $\mathrm{C} / \mathrm{EBP} \beta$ and $\mathrm{C} / \mathrm{EBP} \delta$ activates $\mathrm{C} / \mathrm{EBP} \alpha$ expression. Then, $\mathrm{C} / \mathrm{EBP} \alpha$ and PPAR $\gamma$ activate expression of hundreds of genes responsible for terminal adipocyte differentiation. $\mathrm{C} / \mathrm{EBP} \alpha$ has two main isoforms produced by translation from two in-frame alternative translational initiation sites of the same mRNA, referred to as C/EBPop42 and C/EBPap30 [15]. C/EBPap30 is without the N-terminal $12 \mathrm{kDa}$ of C/EBPap42, lacks the transcriptional activity of C/EBP $\alpha p 42$ and sometimes acts as a dominant-negative form of C/EBP $\alpha$ p42 [16, 17]. Usually, the full-length C/EBPap42 is mentioned as $\mathrm{C} / \mathrm{EBP} \alpha$, which plays essential roles in adipocyte differentiation [18-20].

During adipogenesis, SIRT1 expression is increased 
[11]. But the underlying regulatory mechanism is still unclear. Foxo3a and p53 are responsible for SIRT1 increase during nutrient starvation [3], and SIRT1 increase induced by DNA damage drugs is controlled by E2F 1 [21]. In this study, we found that $\mathrm{C} / \mathrm{EBP} \alpha$ regulates SIRT1 expression during adipogenesis.

\section{Results}

SIRT1 increases along with $C / E B P \alpha$ in the process of 3T3-L1 cell differentiation

The protein level of SIRT1 was reported to increase during adipogenesis of 3T3-L1 cells [22]. Similarly, we observed that the protein level of SIRT1 was elevated in the process of adipogenesis accompanied with the increase of $\mathrm{C} / \mathrm{EBP} \alpha$ protein level (Figure 1A). At the same time, the mRNA level of SIRT1 was also gradually elevated on days 2 and 4 (Figure 1B and 1C). This result suggests that the increase of SIRT1 protein level could be due to the increase of SIRTI mRNA level. In undifferentiated 3T3-L1 preadipocytes, SIRT1 was almost equally immunostained in different cells (Figure 1D, upper panel). The protein level of SIRT1 was dramatically upregulated in differentiated 3T3-L1 cells, which were marked with the positive immunostaining of $\mathrm{C} / \mathrm{EBP} \alpha$ as well as the appearance of lipid droplets (Figure 1D, lower panel). The immunostaining of SIRT1 in undifferentiated cells was very weak (Figure 1D). These data demonstrate that SIRT1 expression only significantly increased in adipogenic cells, and exclude the possibility that the increase of SIRT1 level is induced by adipogenic inducers in undifferentiated cells. Taken together, these results suggest
A

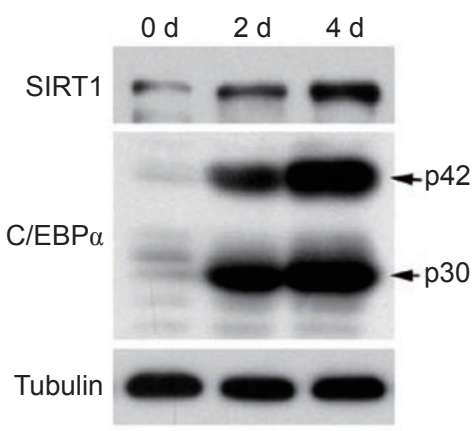

D
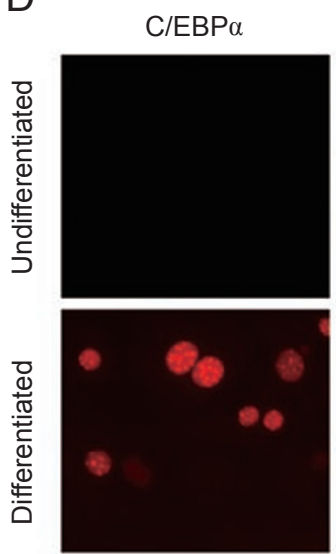

B

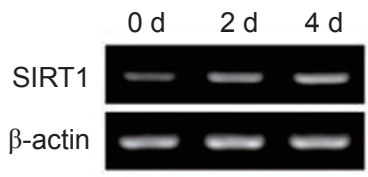

C

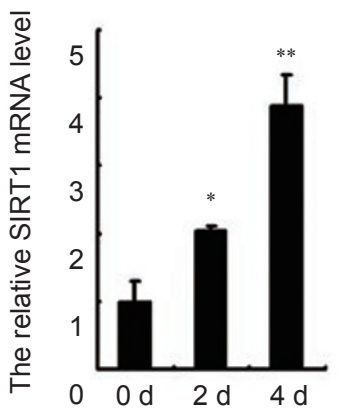

Figure 1 SIRT1 expression increases during the process of 3T3-L1 preadipocytes differentiating into adipocytes. (A) Western blot showed that the protein level of SIRT1 increased during differentiation of 3T3-L1 cells into adipocytes. C/EBP $\alpha$ as a marker of adipogenesis and tubulin as the loading control were also analyzed by western blot. (B) Semi-quantitative RT-PCR showed that the mRNA level of SIRT1 was also elevated during adipogenesis in 3T3-L1 preadipocytes. $\beta$-actin was examined as the internal control. (C) The mRNA level of SIRT1 during adipogenesis of 3T3-L1 preadipocytes was further confirmed by real-time PCR. $* P<0.05, * * P<0.01$, compared with day 0 . (D) SIRT1 protein level increased in differentiated 3T3-L1 cells, but not in undifferentiated cells. 3T3-L1 cells undifferentiated (upper panel) or induced to undergo adipogenesis for 4 days (lower panel) were immunostained to label C/EBP $\alpha$ and SIRT1. SIRT1 protein level greatly increased in cells positively stained for $\mathrm{C} / \mathrm{EBP} \alpha$, in which lipid drops were seen under phase-contrast microscope. Scale bar $=20 \mu \mathrm{m}$. 
that SIRT1 expression might be upregulated by $\mathrm{C} / \mathrm{EBP} \alpha$ in adipogenic cells, likely at the transcriptional level.

\section{C/EBP $\alpha$ activates SIRT1 promoter}

To identify the possible transcription factors responsible for SIRT1 upregulation during adipogenesis, a reporter construct containing a $2852 \mathrm{bp}$ region of the SIRT1 promoter was applied to detect the SIRT1 promoter activity. The C/EBP family transcription factors, including $\mathrm{C} / \mathrm{EBP} \beta, \mathrm{C} / \mathrm{EBP} \alpha \mathrm{p} 30, \mathrm{C} / \mathrm{EBP} \alpha$ and $\mathrm{CHOP}-10$, were reported to increase during adipogenesis [23] and thus were examined in our luciferase assay. As shown in Figure 2A, the SIRT1 promoter was activated by $\mathrm{C} / \mathrm{EBP} \alpha$ by about 9 -fold in HeLa cells, but not by C/EBP $\beta, \mathrm{C} /$ EBPap30 or CHOP-10. The expression of these C/EBP family proteins was confirmed by western blot (Figure 2B). Moreover, the SIRT1 promoter was dose-dependently activated by $\mathrm{C} / \mathrm{EBP} \alpha$, and was not activated by $\mathrm{C} /$
EBP $\alpha$ 30 (Figure 2C). In addition, $\mathrm{C} / \mathrm{EBP} \alpha$ dramatically activated the SIRT1 promoter in 3T3-L1 preadipocytes (Figure 2D). These data suggest that $\mathrm{C} / \mathrm{EBP} \alpha$ is involved in regulating SIRT1 transcription.

C/EBPa upregulates endogenous SIRT1 expression independently of $p 53$

To further investigate the effect of $\mathrm{C} / \mathrm{EBP} \alpha$ on SIRT1 transcription, $\mathrm{C} / \mathrm{EBP} \alpha$ was overexpressed in HeLa cells, and C/EBPap30 was used as the negative control. As shown in Figure 3A, SIRT1 mRNA level was elevated in the cells transfected with $\mathrm{C} / \mathrm{EBP} \alpha$, but not in the cells transfected with $\mathrm{C} / \mathrm{EBP} \alpha \mathrm{p} 30$. Overexpression of $\mathrm{C} / \mathrm{EBP} \alpha$ upregulated the SIRT1 mRNA level by about 2-fold when compared with the cells transfected with the control vector (Figure 3B). Similarly, the effect of $\mathrm{C} / \mathrm{EBP} \alpha$ on the protein level of SIRT1 was examined by immunostaining in HeLa cells. As shown in Figure 3C, no significant
A

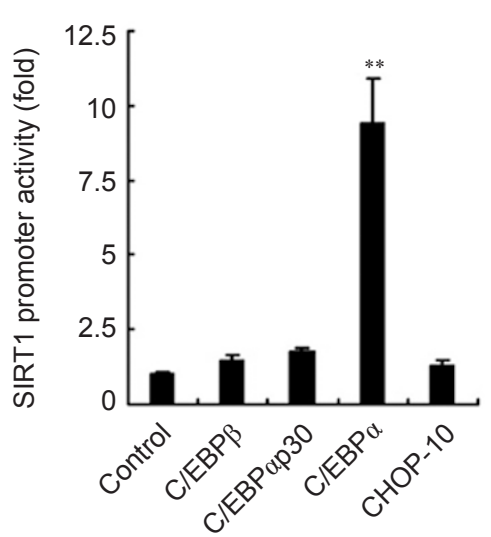

C

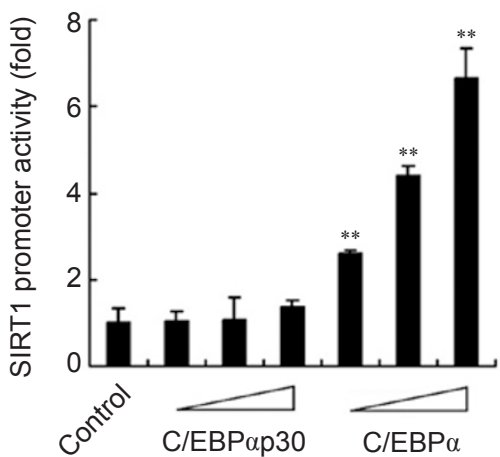

$\mathrm{B}$

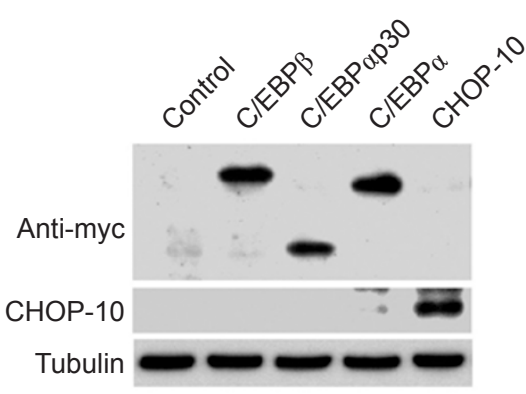

D

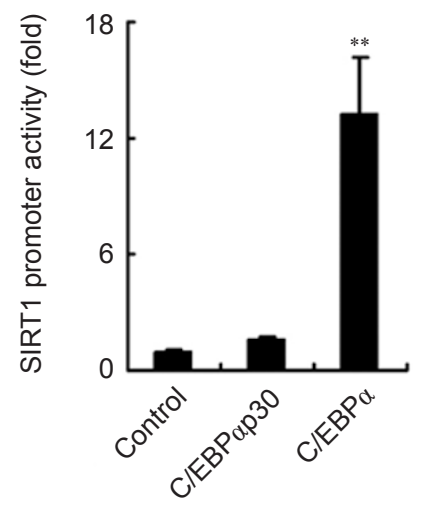

Figure 2 C/EBP $\alpha$ activates SIRT1 promoter. (A) Luciferase activity under the control of 2852 bp SIRT1 promoter in HeLa cells was significantly activated by $\mathrm{C} / \mathrm{EBP} \alpha$, but not by $\mathrm{C} / \mathrm{EBP} \beta, \mathrm{C} / \mathrm{EBP} \alpha \mathrm{p} 30$ or $\mathrm{CHOP}-10$. ** $P<0.01$, compared with the control cells transfected with empty vector. (B) Western blot showed the expression of proteins in samples from $\mathbf{A}$. (C) 2852 bp SIRT1 promoter was dose-dependently activated by C/EBP $\alpha$, but not by C/EBPap30. ** $P<0.01$, compared with the control cells. (D) C/EBP $\alpha$ markedly activated the 2852 bp SIRT1 promoter in 3T3-L1 preadipocytes. ** $P<0.01$, compared with the cells transfected with empty vector (control) or with C/EBPap30. 
A

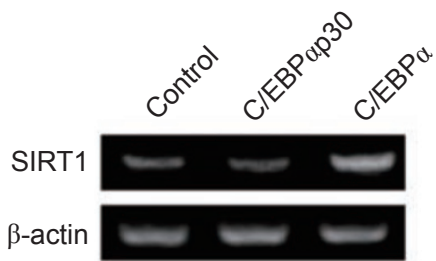

C
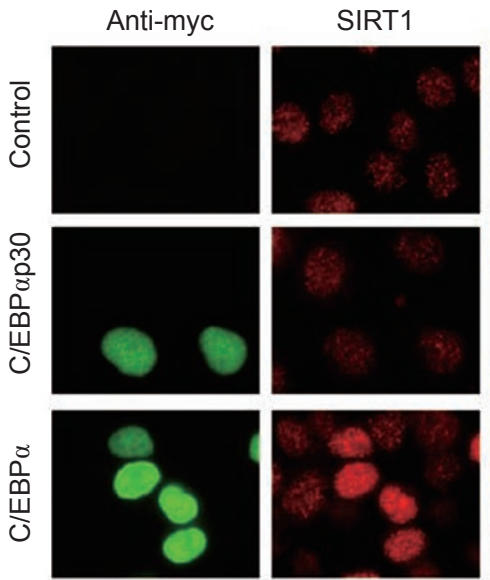

$E$
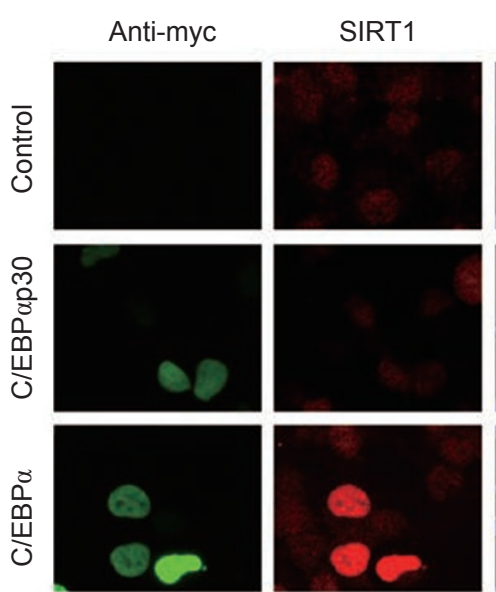

B

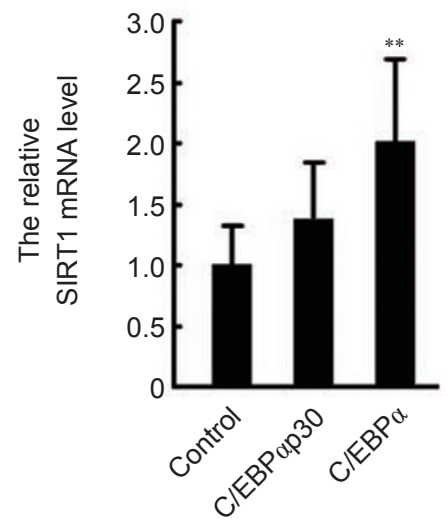

D

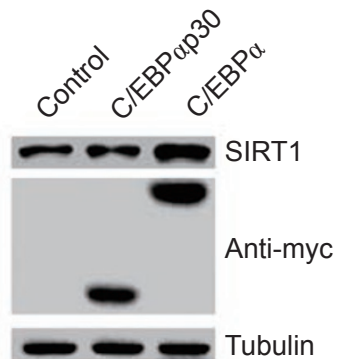

Hoechst 33258
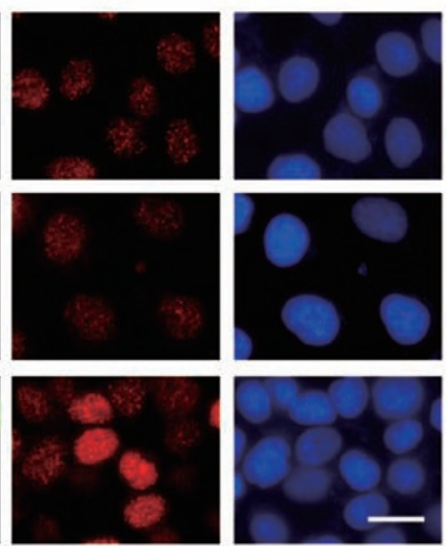

Hoechst $33258 F$

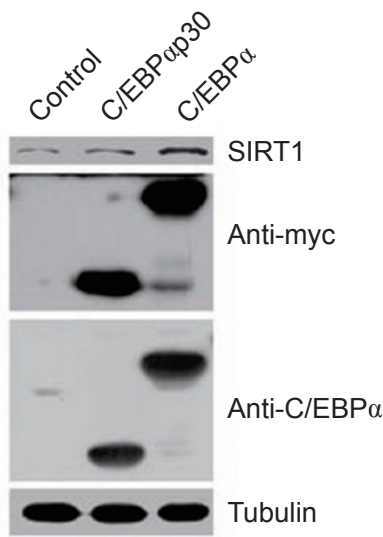

Figure 3 Ectopic C/EBP $\alpha$ stimulates endogenous SIRT1 expression. (A) Semi-quantitative RT-PCR showed that SIRT1 mRNA level increased in HeLa cells transfected with C/EBP $\alpha$, but not in cells transfected with C/EBPap30. $\beta$-actin was examined as the internal control. (B) SIRT1 mRNA level affected by C/EBP $\alpha$ in HeLa cells was further confirmed by real-time PCR. ** $P<0.01$, compared with the cells transfected with empty vector (Control) or C/EBPap30 by paired Student's $t$-test. (C) Fluorescence immunostaining showed that the SIRT1 protein level increased in HeLa cells transfected with C/EBP $\alpha$, but not in cells transfected with C/EBPap30. The expression of SIRT1 and Myc-tagged C/EBPap30 or C/EBP $\alpha$ was detected by antiSIRT1 or anti-Myc antibody, respectively. Scale bar $=20 \mu \mathrm{m}$. (D) Western blot showed that the SIRT1 protein level increased in HeLa cells transfected with C/EBP $\alpha$, but not with C/EBPap30. Exogenous C/EBP $\alpha$ expression was recognized by anti-Myc antibody. (E, F) C/EBP $\alpha$ also upregulated SIRT1 expression in Soas-2 cells lacking the functional p53, when detected by both immunofluorescence $(\mathbf{E})$ and western blot $(\mathbf{F})$. Scale bar $=20 \mu \mathrm{m}$. 
change of the SIRT1 immunofluorescence was observed when the cells were transfected with empty vector or C/ EBP $\alpha$ p30. By contrast, the SIRT1 protein level in the cells expressing exogenous $\mathrm{C} / \mathrm{EBP} \alpha$ was significantly increased compared with that in the cells without exogenous $\mathrm{C} / \mathrm{EBP} \alpha$ expression in the same field (Figure 3C, lower panel). The effect of $\mathrm{C} / \mathrm{EBP} \alpha$ on the protein level of SIRT1 was also confirmed by western blot. As shown in Figure 3D, overexpression of $\mathrm{C} / \mathrm{EBP} \alpha$, but not of $\mathrm{C} /$ EBP $\alpha$ 30, significantly increased the SIRT1 protein level. These results demonstrate that $\mathrm{C} / \mathrm{EBP} \alpha$ is capable of inducing endogenous SIRT1 mRNA transcription and its protein expression.

It was reported that acute nutrient withdrawal activated Foxo3a to induce p53-mediated SIRT1 expression [24]. To examine whether p53 is involved in C/EBP $\alpha$ dependent SIRT1 expression, we tested the effect of $\mathrm{C} /$ EBP $\alpha$ on SIRT1 expression in Soas-2 cells lacking the functional p53. Consistent with the result of Figure 3C, the SIRT1 protein level in the Soas-2 cells expressing exogenous $\mathrm{C} / \mathrm{EBP} \alpha$ was significantly increased compared with that in the cells without exogenous $\mathrm{C} / \mathrm{EBP} \alpha$ expression in the same field (Figure $3 \mathrm{E}$ ). These results were further confirmed by western blot, and the expression of $\mathrm{C} / \mathrm{EBP} \alpha$ and $\mathrm{C} / \mathrm{EBP} \alpha \mathrm{p} 30$ was validated using anti-C/ $\mathrm{EBP} \alpha$ antibody (Figure 3F). These results show that $\mathrm{C} /$ $\mathrm{EBP} \alpha$ is capable of upregulating SIRT1 expression in a p53-independent manner.

\section{$C / E B P \alpha$ regulates SIRT1 expression in preadipocytes}

To further confirm the effect of C/EBP $\alpha$ on SIRT1 expression in preadipocytes, the plasmids encoding $\mathrm{C} /$ $\mathrm{EBP} \alpha, \mathrm{C} / \mathrm{EBP} \alpha \mathrm{p} 30, \mathrm{C} / \mathrm{EBP} \beta$ or $\mathrm{CHOP}-10$ were transfected into 3T3-L1 preadipocytes. As shown in Figure $4 \mathrm{~A}$, overexpression of $\mathrm{C} / \mathrm{EBP} \alpha$, but not $\mathrm{C} / \mathrm{EBP} \alpha \mathrm{p} 30, \mathrm{C} /$ $\mathrm{EBP} \beta$ or CHOP-10, resulted in the increase of SIRT1 protein level. Although $\mathrm{C} / \mathrm{EBP} \alpha$ was very difficult to be detected in 3T3-L1 preadipocytes (data not shown), C/ $\mathrm{EBP} \alpha$ was expressed and detectable in primary cultured rat preadipocytes (Figure 4B) as described previously [25]. To further investigate whether $\mathrm{C} / \mathrm{EBP} \alpha$ is important for regulation of SIRT1 expression, lentivirus expressing $\mathrm{C} / \mathrm{EBP} \alpha$ RNAi was used to infect primary cultured rat preadipocytes. 3 days after infection, SIRT1 expression declined accompanied with the decrease of $\mathrm{C} / \mathrm{EBP} \alpha$, when analyzed by western blot (Figure 4C). These results demonstrate that $\mathrm{C} / \mathrm{EBP} \alpha$ plays an important role in regulation of SIRT1 expression in preadipocytes.

\section{$C / E B P \alpha$ directly binds to SIRT1 promoter and upregu- lates SIRT1 transcription}

To identify the underlying mechanism by which $\mathrm{C} /$

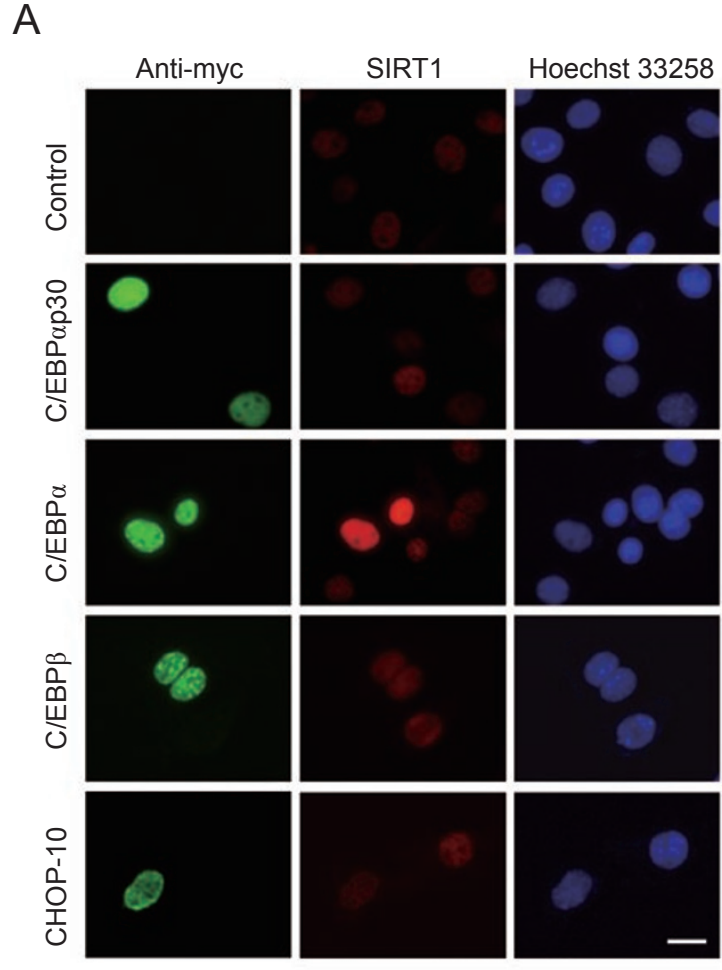

B

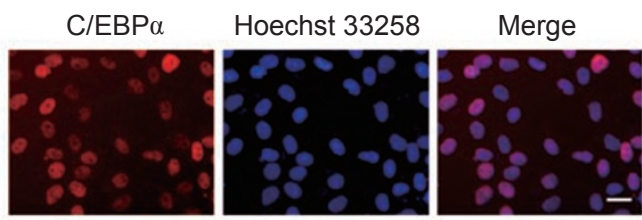

C

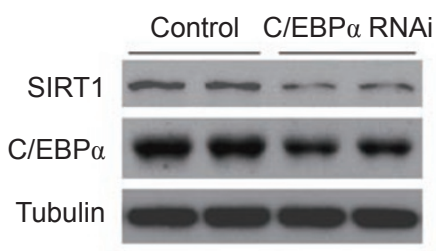

Figure $4 \mathrm{C} / \mathrm{EBP} \alpha$ regulates SIRT1 expression in preadipocytes. (A) Overexpression of $\mathrm{C} / \mathrm{EBP} \alpha$ upregulated SIRT1 expression in 3T3-L1 preadipocytes, but C/EBPap30, C/EBP $\beta$ and CHOP10 did not. Scale bar $=20 \mu \mathrm{M}$. (B) Fluorescence immunostaining using anti-C/EBP $\alpha$ antibody showed that $\mathrm{C} / \mathrm{EBP} \alpha$ was expressed in nearly all rat preadipocytes. Nuclei were stained with Hoechst 33258 (Hoechst). Scale bar $=10 \mu \mathrm{m}$. (C) SIRT1 was downregulated in rat preadipocytes infected with lentivirus expressing C/EBP $\alpha$ RNAi.

EBP $\alpha$ upregulates SIRT1 transcription, a series of SIRT1 promoter fragments were used to examine the effect of $\mathrm{C} / \mathrm{EBP} \alpha$ on SIRT1 promoter activity. As shown in Figure $5 \mathrm{~A}$, successive deletions of SIRT1 promoter revealed that $\mathrm{C} / \mathrm{EBP} \alpha$ greatly activated the SIRT1 promoter fragment 
between positions -629 and -372 . This result suggests that potential $\mathrm{C} / \mathrm{EBP} \alpha$ binding sites may exist between positions -629 and -372 . Two potential $\mathrm{C} / \mathrm{EBP} \alpha$ binding sites at positions -567 to -550 and -426 to -409 were
A

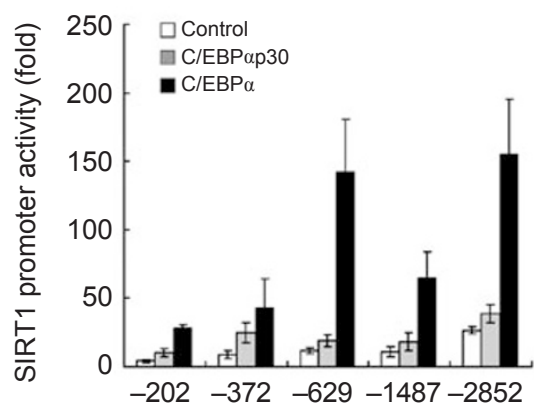

C

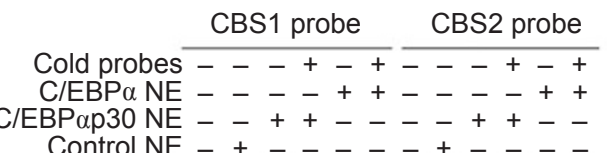

Control NE ++----++--

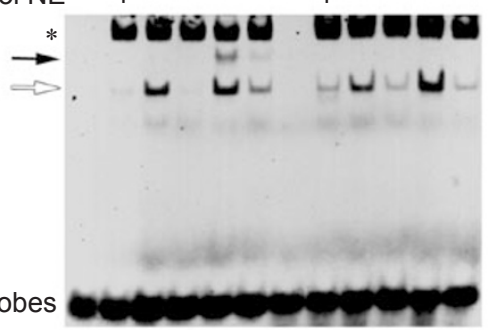

F

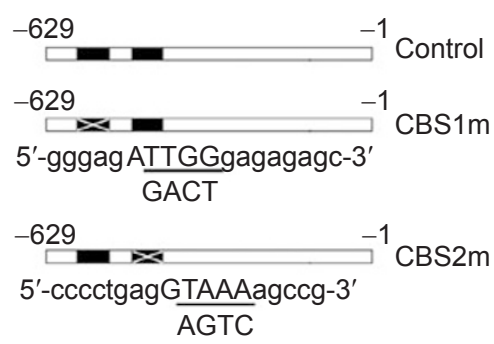

B
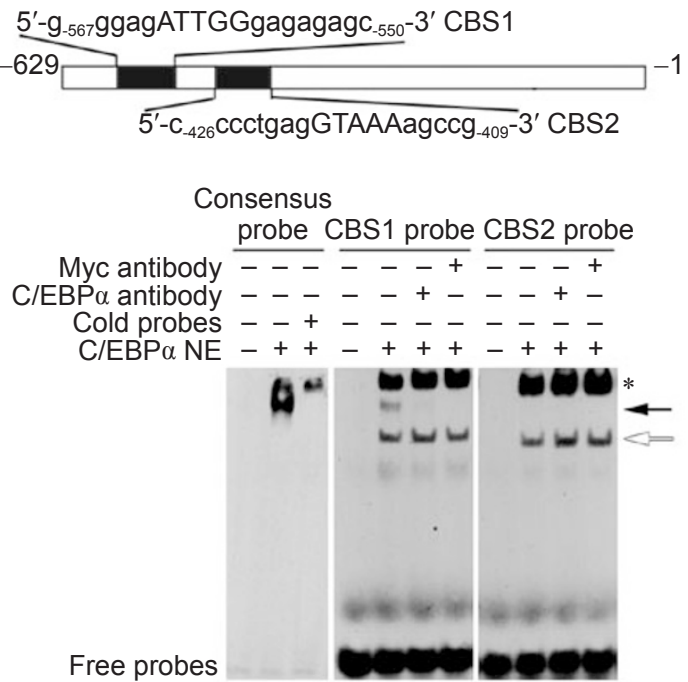

E

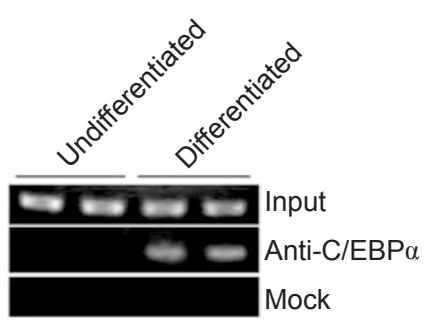

$\mathrm{H}$

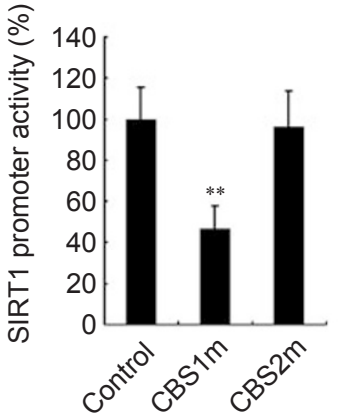

Figure $5 \mathrm{C} / \mathrm{EBP} \alpha$ binds to SIRT1 promoter. (A) The effect of C/EBP $\alpha$ and C/EBP $\alpha$ 30 on the luciferase expression under the control of a series of SIRT1 promoter fragments in HeLa cells. (B) Schematic of the 629 bp SIRT1 promoter fragment, showing two potential C/EBP binding sites (CBS), at -550 (CBS1) and -409 (CBS2). (C) EMSA showed that C/EBP $\alpha$, but not C/ EBPap30, bound to the CBS1 probe, and neither bound to the CBS2 probe. * and open arrow indicate nonspecific bands; solid arrow indicates C/EBP $\alpha$ binding bands, as confirmed by (D). (D) C/EBP $\alpha$ binding bands were further confirmed by $\mathrm{C} /$ EBP $\alpha$ consensus probe and supershift. * and open arrow indicate nonspecific bands; solid arrow indicates C/EBP $\alpha$ binding bands. (E) ChIP assay showed that CBS1 region in SIRT1 promoter was coprecipitated with anti-C/EBP $\alpha$ antibody in 3T3-L1 cells differentiated for 5 days. (F) Schematic of the 629 bp SIRT1 promoter fragment, showing the CBS1 mutation (CBS1m) and CBS2 mutation (CBS2m). The underlined sequences were mutated to the sequences given under the lines. (G) Mutation of CBS1 significantly inhibited C/EBP $\alpha$ induced activation of the 629 bp SIRT1 promoter. $* * P<0.01$, compared with the wild-type 629 bp SIRT1 promoter. (H) Binding of C/EBP $\alpha$ to SIRT1 promoter was upregulated in mouse white adipose tissue under fasting condition. ${ }^{* *} P<0.01$, compared with the mice fed ad libitum. 
predicted using the Match algorithm (http://www.generegulation.com/cgi-bin/pub/programs/match). These two sites were named as $\mathrm{C} / \mathrm{EBP} \alpha$ binding site 1 (CBS1) and 2 (CBS2), respectively (Figure 5B).

To test whether $\mathrm{C} / \mathrm{EBP} \alpha$ could bind to $\mathrm{CBS} 1$ or CBS2, CBS1 and CBS2 were synthesized and labeled to perform electrophoretic mobility shift assay (EMSA). As shown in Figure 5C, two possible $\mathrm{C} / \mathrm{EBP} \alpha$ binding bands appeared and were indicated with a solid or open arrow. Both of the bands could be competed off by respective cold probes. The band indicated with the solid arrow only appeared when the samples transfected with $\mathrm{C} / \mathrm{EBP} \alpha$ were applied to CBS1 probe binding. Almost equal expression of $\mathrm{C} / \mathrm{EBP} \alpha$ and $\mathrm{C} / \mathrm{EBP} \alpha \mathrm{p} 30$ in nuclear extracts was confirmed by western blot (data not shown). To further identify the specific $\mathrm{C} / \mathrm{EBP} \alpha$ binding bands, a consensus CBS probe with the same length of CBS1 or CBS2 probe was applied as a positive control. As shown in Figure 5D left panel, in the two possible binding bands, only the band indicated with the solid arrow appeared. Although the molecular weight was different between $\mathrm{C} / \mathrm{EBP} \alpha$ and $\mathrm{C} / \mathrm{EBP} \alpha \mathrm{p} 30$, the shift distance in EMSA assay was not significantly different [15]. Thus, it was unlikely that the band indicated by the open arrow was due to C/EBPap30 binding. Furthermore, as C/ $\mathrm{EBP} \alpha$ was tagged with myc, anti-myc and anti-C/EBP $\alpha$ antibodies were used in the supershift assay. As shown in Figure 5D middle and right panels, only the band indicated by the solid arrow disappeared when the indicated antibodies were added in the reaction. Therefore, the band indicated with the solid arrow was the specific band, and all other bands are nonspecific bands. Together with the results in Figure 5C, these data suggest that the CBS1 site is the $\mathrm{C} / \mathrm{EBP} \alpha$ binding element in SIRT1 promoter, and C/EBPap30 does not bind to CBS1. This is consistent with our results that C/EBP $\alpha$ p30 does not regulate SIRT1 expression. To test the in vivo binding of $\mathrm{C} /$ EBP $\alpha$ to the CBS1 site, we performed chromatin immunoprecipitation (ChIP) assay with anti-C/EBP $\alpha$ antibody. As shown in Figure 5E, the SIRT1 promoter fragment containing the CBS1 site was coprecipitated with endogenous $\mathrm{C} / \mathrm{EBP} \alpha$ in differentiated 3T3-L1 adipocytes. Taken together, $\mathrm{C} / \mathrm{EBP} \alpha$ was demonstrated to bind to the CBS1 site of SIRT1 promoter both in vitro and in vivo.

To examine whether the CBS1 site is important for SIRT1 promoter activation, CBS1 and CBS2 were mutated in the $629 \mathrm{bp}$ SIRT1 promoter and tested in the promoter activity assay (Figure 5F). Only mutation of the CBS1 site significantly inhibited the activation of SIRT1 promoter by $\mathrm{C} / \mathrm{EBP} \alpha$ (Figure $5 \mathrm{G}$ ). This is consistent with the results from the EMSA assay that $\mathrm{C} / \mathrm{EBP} \alpha$ only binds to the CBS1 site.
SIRT1 has been reported to be upregulated in mouse white adipose tissue under fasting condition [8]. To test whether the increase of SIRT1 transcription in mouse white adipose tissue under fasting condition is associated with binding of $\mathrm{C} / \mathrm{EBP} \alpha$ to the $\mathrm{CBS} 1$ site of SIRT1 promoter, we performed ChIP assay with anti-C/EBP $\alpha$ antibody using white adipose tissue from mice fed $a d$ libitum, fasted for $24 \mathrm{~h}$ or refed for $2 \mathrm{~h}$ after $24 \mathrm{~h}$ of fasting. As expected, binding of $\mathrm{C} / \mathrm{EBP} \alpha$ to the $\mathrm{CBS} 1$ region of SIRT1 promoter was enhanced by fasting, and then attenuated by re-feeding (Figure $5 \mathrm{H}$ ).

All these results illustrate that $\mathrm{C} / \mathrm{EBP} \alpha$ directly binds to the CBS1 site of SIRT1 promoter to upregulate SIRT1 transcription.

\section{Discussion}

It has been reported that SIRT1 transcription is regulated by p53 and Foxo3a under fasting conditions [24] or regulated by E2F1 in response to DNA damage [21]. Here, we demonstrate that SIRT1 expression is regulated by $\mathrm{C} / \mathrm{EBP} \alpha$ during adipogenesis. We observed that SIRT1 protein level increased along with $\mathrm{C} / \mathrm{EBP} \alpha$ during adipocyte differentiation (Figure 1), which is consistent with the previous report [22]. Overexpression of $\mathrm{C} / \mathrm{EBP} \alpha$ was sufficient to increase SIRT1 expression in different cells, whereas knockdown of $\mathrm{C} / \mathrm{EBP} \alpha$ by RNAi in rat preadipocytes led to decrease of SIRT1 protein level (Figures 3 and 4). Furthermore, we identified a C/EBP $\alpha$ binding site in the SIRT1 promoter (Figure 5). However, the SIRT1 promoter containing the 372 or $202 \mathrm{bp}$ fragment without the identified binding site was still activated by $\mathrm{C} / \mathrm{EBP} \alpha$. These data indicate that there should be other $\mathrm{C} / \mathrm{EBP} \alpha$ binding sites in the SIRT1 promoter. In addition, we found that SIRT1 level increased along with $\mathrm{C} / \mathrm{EBP} \alpha$ in white adipose tissue from mice fasted overnight (data not shown) and the binding of $\mathrm{C} / \mathrm{EBP} \alpha$ to SIRT1 promoter was enhanced by fasting (Figure $5 \mathrm{H}$ ), suggesting that $\mathrm{C} / \mathrm{EBP} \alpha$ might regulate SIRT1 transcription in adipose tissue in vivo. All these results show that $\mathrm{C} / \mathrm{EBP} \alpha$ is an important regulator of SIRT1 transcription, in addition to p53, Foxo3a and E2F1 [21, 24].

During the process of adipocyte differentiation, $\mathrm{C} /$ $\mathrm{EBP} \alpha$ and PPAR $\gamma$ are master adipogenic factors [26]. Overexpression of SIRT1 repressed PPAR $\gamma$ and $\mathrm{C} / \mathrm{EBP} \alpha$, and as a result inhibited adipogenesis in 3T3-L1 cells [11]. In this study, we found that $\mathrm{C} / \mathrm{EBP} \alpha$ stimulated the transcription of SIRT1. Similarly, C/EBP $\alpha$ also stimulates the expression of $\beta 3$-adrenergic receptor, which can stimulate lipolysis [27]. In addition, we found that the binding of C/EBP $\alpha$ to SIRT1 promoter was enhanced after fasting (Figure 5), which is consistent with previous studies 
showing that SIRT1 repressed PPAR $\gamma$ after starvation to promote fat mobilization $[11,28]$. Therefore, it is likely that $\mathrm{C} / \mathrm{EBP} \alpha$ might stimulate adipogenesis and also induce other genes to gradually suppress adipogenesis, thus to control adipocyte differentiation at an appropriate degree to maintain the adipose homeostasis in vivo. In addition to acting as a master adipogenic transcription factor, $\mathrm{C} / \mathrm{EBP} \alpha$ is required to confer insulin sensitivity to the adipocyte [29]. SIRT1 plays an important role in insulin sensitivity [9]. PPAR $\gamma$ agonists have been already applied in clinic to promote insulin sensitivity [30]. All these findings implicate that SIRT1, C/EBP $\alpha$ and PPAR $\gamma$ might coordinate to regulate adipogenesis as well as insulin sensitivity in adipocytes. Future studies focused on how adipogenesis is naturally terminated to control the lipid accumulation in adipocytes should provide new approaches for preventing or treating obesity.

\section{Materials and Methods}

\section{Plasmids \\ pcDNA-C/EBP $\alpha$ and pcDNA-C/EBP $\alpha$ p 30 expressing two isoforms of $\mathrm{C} / \mathrm{EBP} \alpha, \mathrm{C} / \mathrm{EBP} \alpha$ and $\mathrm{C} / \mathrm{EBP} \alpha \mathrm{p} 30$, respectively; and pcDNA-C/EBP $\beta$ expressing $\mathrm{C} / \mathrm{EBP} \beta$ were all kindly provided by $\mathrm{G} \mathrm{Hu}$ [31]. pCS2+-SIRT1 expressing SIRT1 was constructed by insertion of SIRT1 cDNA fragment cut from pBabepuro-SIRT1 [4] into $\mathrm{pCS} 2+$ at the BamHI site. pcDNA-CHOP-10 expressing hu- man CHOP-10 was constructed by insertion of $C H O P-10$ cDNA fragment into pCDNA3.1/myc-His(-) B (Invitrogen) at EcoRI and BamHI sites. CHOP-10 cDNA fragment was amplified by RT-PCR using RNA extracted from HeLa cells with 5'-CGG AAT TCA TGA GCG GGT GGC AGC GA-3' and 5'-GCG GAT CCC TTG GTG CAG ATT CAC CAT TCG-3' as primers. pTA-202bp, pTA-372bp, pTA-629bp, pTA-1487bp and pTA-2852bp SIRT1 promoters containing various SIRT1 promoter fragments, which began at position $-202,-372,-629,-1487$ or -2852 relative to the translation start site, were kindly provided by T Finkel [24]. pGL3-629bp SIRT1 promoter containing 629 bp SIRT1 promoter was constructed by insertion of the $629 \mathrm{bp}$ SIRT1 promoter frag- ment to pGL3-basic (Promega) at KpnI and XhoI sites. The 629 bp SIRT1 promoter fragment was amplified by PCR from pTA-629bp SIRT1 promoter using 5'-GGG GTA CCG ATC TTT CCA GGA GGG CAA C- $3^{\prime}$ and 5'-CCG CTC GAG CTT CCA ACT GCC TCT CTG GC- $3^{\prime}$ as primers.}

\section{Cell culture, transfection and induction of 3T3-L1 adipo- genesis}

HeLa, Soas-2, HEK293T and 3T3-L1 preadipocytes cells were grown in DMEM with $10 \%$ newborn calf serum. The preadipocytes were prepared from epididymal, subcutaneous and mesenteric adipose tissue from about 7-week-old male SD rats according to a method previously described [32], and cultured in DMEM + F12 (1:1) with $10 \%$ FBS. Rats were obtained from Slaccas (Shanghai, China), and used in accordance with the guidelines of the Institutional Animal Care and Use Committee of the Institute for Nutritional Sciences. Transfection was performed with lipofectamine
2000 according to the manufacturer's instruction. To differentiate 3T3-L1 cells, after growing them to confluence, the cells were allowed to grow for 2 days, and then exposed to fresh differentiation medium containing DMEM, 10\% FBS, $1 \mu \mathrm{M}$ dexamethasone, 0.5 $\mathrm{mM} 3$-isobutyl-1-methylxanthine, $10 \mu \mathrm{M}$ troglitazone and $1 \mu \mathrm{g} / \mathrm{ml}$ insulin. After 2 days, the cells were refed with fresh DMEM containing $10 \% \mathrm{FBS}, 10 \mathrm{mM}$ troglitazone and $1 \mu \mathrm{g} / \mathrm{ml}$ of insulin for another 2 days. Then, the cells were cultured in DMEM with $10 \%$ FBS.

\section{Western blot}

Western blot was carried out as previously described [33], using rabbit anti-C/EBP $\alpha$ antibody (1:500), mouse anti-Myc antibody (1:1 000) from Santa Cruz Biotechnology; rabbit anti-SIRT1 antibody (1:10 000) from Upstate, mouse anti-tubulin antibody (1:10 000) from Sigma, mouse anti-CHOP-10 antibody (1:500) from Abcam and secondary antibodies conjugated to horseradish peroxidase (1:1 000) from Jackson ImmunoResearch. The bound immune complexes were detected with SuperSignal west pico chemiluminescent substrate (Pierce).

\section{$R N A$ extraction and $R T-P C R$}

RNA was extracted with Trizol and reverse transcribed to cDNA. SIRT1 and $\beta$-actin were detected by PCR using 5 '-CCT GAC TTC AGA TCA AGA GAC GGT A-3' and 5'-CTG ATT AAA AAT GTC TCC ACG AAC AG-3' as primers for mouse SIRT1; 5'-TGC CGC ATC CTC TTC CTC-3' and 5'-GTC GCC TTC ACC GTT CCA-3' for mouse $\beta$-actin; 5 '-GCA ACA TCT TAT GAT TGG CAC AG-3' and 5'-TTT GGA TTC CCG CAA CCT G-3' for human SIRT1; and 5'-TGC TGT CCC TCT ACG CCT CTG-3' and 5'-GCC GCA AGA TTC CAT ACC C-3' for human $\beta$-actin. Real-time PCR was performed using $5^{\prime}$-GCC AGA GTC CAA GTT TAG AAG A-3' and 5'-CCA TCA GTC CCA AAT CCA G-3' as primers for human SIRT1; 5'-TGA CGT GGA CAT CCG CAA AG-3' and 5'-CTG GAA GGT GGA CAG CGA GG-3' for human actin as internal control; 5'-CAC ATG CCA GAG TCC AAG TT-3' and 5'-AAA TCC AGA TCC TCC AGC AC-3' for mouse SIRT1; and 5'-CAC TGG TCT AGG ACC CGA GAA-3' and 5'-AGG GGG AGA TGT TCA GCA TGT-3' for mouse 36b4 as internal control.

\section{Immunofluorescence}

Immunofluorescence was performed as previously described [34]. Differentiated 3T3-L1 cells were stained by rabbit anti-C/ EBP $\alpha$ antibody (1:500) and mouse anti-SIRT1 antibody (Sigma, 1:1 000), rat preadipocytes were stained by rabbit anti-C/EBP $\alpha$ antibody (1:500) and other cells were stained by mouse anti-Myc antibody (1:1 000) and rabbit anti-SIRT1 antibody (1:10 000). After incubation with Cy3 conjugated anti-rabbit IgG (Jackson ImmunoResearch) and/or Alexa fluor 488 conjugated anti-mouse IgG (Invitrogen, 1:1 000), the cells were stained with Hoechst 33258 $(0.25 \mu \mathrm{g} / \mathrm{ml})$. Images were acquired at room temperature on a microscope (Olympus IX71).

\section{Luciferase assay}

After transfection for $24 \mathrm{~h}, \mathrm{HeLa}$ cells in 24-well plates were harvested for luciferase assay. A $\beta$-galactosidase-expressing plasmid from Promega was included in each transfection to monitor the transfection efficiency. The transfected plasmids were bal- 
anced with empty vector. Luciferase activities were determined by luciferase assay kit from Promega. Luciferase activity was normalized to $\beta$-galactosidase activity, which was determined as described previously [35].

\section{Electrophoretic mobility shift assay}

EMSA was performed with a dig gel shift kit (Roche) according to the manufacturer's instruction. The nuclear extracts were prepared from $\mathrm{HeLa}$ cells transfected with empty vector, $\mathrm{C} / \mathrm{EBP} \alpha$ or C/EBP $\alpha$ 30, according to the method described previously [36]. The CBS1 and CBS2 probes, corresponding to the predicted C/ EBP binding sites (CBS) at -567 to -550 and -426 to -409 , relative to the translation start site, are 5'-AGG GAG ATT GGG AGA GAG CG-3' and 5'-GCC CCT GAG GTA AAA GCC GA-3', respectively. Consensus $\mathrm{C} / \mathrm{EBP} \alpha$ binding sequence probe is $5^{\prime}-\mathrm{TGC}$ AGA TTG CGC AAT CTG CA-3'. Mouse anti-myc antibody and rabbit anti-C/EBP $\alpha$ antibody were used for supershift assay.

\section{Preparation of recombinant lentivirus}

pLentiLox 3.7-H1 with the $\mathrm{H} 1$ promoter and pLentiLox 3.7$\mathrm{H} 1$ containing Renilla luciferase RNAi were obtained as described previously [9]. To construct a plasmid expressing $\mathrm{C} / \mathrm{EBP} \alpha \mathrm{RNAi}$, 5'-GAT CCG AAG TCG GTG GAC AAG AAC TTC AAG AGA GTT CTT GTC CAC CGA CTT CTT TTT TGG AAG-3' and 5'TCG ACT TCC AAA AAA GAA GTC GGT GGA CAA GAA CTC TCT TGA AGT TCT TGT CCA CCG ACT TCG-3' were annealed and cloned into pLentiLox 3.7-H1 at BamH1 and XhoI sites. The recombinant lentivirus were packaged and harvested as described previously [9]. Rat preadipocytes were infected with lentivirus in the presence of $8 \mu \mathrm{g} / \mathrm{ml}$ polybrene for $12 \mathrm{~h}$ each time and totally three times.

\section{Chromatin immunoprecipitation assay}

ChIP assay for cultured cells was performed using a ChIP assay kit from Upstate. Chromatin was immunoprecipitated with anti-C/ EBP $\alpha$ antibody $(1: 200)$. The coprecipitated chromatin was analyzed by PCR using 5'-TTT CCA GGA GGG CAA CAG GC-3' and 5'-GCC TTG CCC TTG CTC TGT G-3' as primers. The PCR product is a fragment of SIRT1 promoter spanning from -625 to -483 . The ChIP assay with white adipose tissues was performed as described previously with modifications [37]. The tissues were minced and fixed for $4 \mathrm{~h}$ in PBS containing $1 \%$ formaldehyde and $1 \mathrm{mM}$ PMSF, $1 \mu \mathrm{g} / \mathrm{ml}$ Aprotinin and $1 \mu \mathrm{g} / \mathrm{ml}$ Pepstatin A. Subsequently, the samples were rinsed twice with PBS and homogenized in $1 \mathrm{ml}$ of ice-cold cell lysis buffer (10 mM Tris- $\mathrm{HCl}(\mathrm{pH} 8.0), 10$ $\mathrm{mM} \mathrm{NaCl}, 3 \mathrm{mM} \mathrm{MgCl}, 0.5 \% \mathrm{NP}-40$ and supplemented with the above protease inhibitors) and then incubated at $4{ }^{\circ} \mathrm{C}$ for $5 \mathrm{~min}$. Then, the samples were centrifuged at $15000 \times \mathrm{g}$ for $10 \mathrm{~min}$, and both the supernatant and the fat were discarded. The pellet was resuspended in 1\% SDS, $5 \mathrm{mM}$ EDTA, $50 \mathrm{mM}$ Tris- $\mathrm{HCl}(\mathrm{pH} 8.1)$ supplemented with protease inhibitors, and sonicated using a Sonic dismembrator with a microtip probe set to power an output of 5-6 $\mathrm{W}$ for 10 cycles of $30 \mathrm{~s}$ on and $40 \mathrm{~s}$ off for each cycle. Then, the samples were used for ChIP assay as cultured cells.

\section{Animals}

All animals were maintained and used in accordance with the guidelines of the Institutional Animal Care and Use Committee of the Institute for Nutritional Sciences. Male C57BL/6 mice at
9 weeks of age were purchased from Slaccas (Shanghai, China). Nine mice were randomly divided into three groups and fed chow (D12450B, Research diets). After 1 week, the mice were fed as usual, fasted for $24 \mathrm{~h}$, or refed $2 \mathrm{~h}$ after $24 \mathrm{~h}$ of fasting. The animals were sacrificed, and the white adipose tissues were removed and snap-frozen for ChIP assay.

\section{Statistical analysis}

Data are expressed as mean \pm SD of at least three independent experiments. Statistical significance was assessed by Student's $t$-test except indicated. Differences were considered statistically significant at $P<0.05$.

\section{Acknowledgments}

This study was supported by grants from the National Natural Science Foundation of China (30825009 and 30970619), the National Basic Research Program of China (973 Program, 2009CB918403 and 2007CB914501), the Chinese Academy of Sciences (KSCX2-YW-N-034, KSCX1-YW-02 and KSCX2-225 ) and the Knowledge Innovation Program of Shanghai Institutes for Biological Sciences (2007KIP103). Q Zhai is a scholar of the Hundred Talents Program of the Chinese Academy of Sciences and a scholar of the Shanghai Rising-Star Program of the Science and Technology Commission of Shanghai Municipality (08QH1402600).

\section{References}

1 Blander G, Guarente L. The Sir2 family of protein deacetylases. Annu Rev Biochem 2004; 73:417-435.

2 Brunet A, Sweeney LB, Sturgill JF, et al. Stress-dependent regulation of FOXO transcription factors by the SIRT1 deacetylase. Science 2004; 303:2011-2015.

3 Cohen HY, Miller C, Bitterman KJ, et al. Calorie restriction promotes mammalian cell survival by inducing the SIRT1 deacetylase. Science 2004; 305:390-392.

4 Luo J, Nikolaev AY, Imai S, et al. Negative control of p53 by Sir2alpha promotes cell survival under stress. Cell 2001; 107:137-148.

5 Vaziri H, Dessain SK, Ng Eaton E, et al. hSIR2(SIRT1) functions as an NAD-dependent p53 deacetylase. Cell 2001; 107:149-159.

6 Guarente L. Sirtuins as potential targets for metabolic syndrome. Nature 2006; 444:868-874.

7 Moynihan KA, Grimm AA, Plueger MM, et al. Increased dosage of mammalian Sir2 in pancreatic beta cells enhances glucose-stimulated insulin secretion in mice. Cell Metab 2005; 2:105-117.

8 Rodgers JT, Lerin C, Haas W, Gygi SP, Spiegelman BM, Puigserver P. Nutrient control of glucose homeostasis through a complex of PGC-1alpha and SIRT1. Nature 2005; 434:113118 .

9 Sun C, Zhang F, Ge X, et al. SIRT1 improves insulin sensitivity under insulin-resistant conditions by repressing PTP1B. Cell Metab 2007; 6:307-319.

10 Fulco M, Schiltz RL, Iezzi S, et al. Sir2 regulates skeletal muscle differentiation as a potential sensor of the redox state. Mol Cell 2003; 12:51-62. 
11 Picard F, Kurtev M, Chung N, et al. Sirtl promotes fat mobilization in white adipocytes by repressing PPAR-gamma. Nature 2004; 429:771-776.

12 Baur JA, Pearson KJ, Price NL, et al. Resveratrol improves health and survival of mice on a high-calorie diet. Nature 2006; 444:337-342.

13 Lagouge M, Argmann C, Gerhart-Hines Z, et al. Resveratrol improves mitochondrial function and protects against metabolic disease by activating SIRT1 and PGC-1alpha. Cell 2006; 127:1109-1122.

14 Farmer SR. Transcriptional control of adipocyte formation. Cell Metab 2006; 4:263-273.

15 Lin FT, MacDougald OA, Diehl AM, Lane MD. A 30-kDa alternative translation product of the CCAAT/enhancer binding protein alpha message: transcriptional activator lacking antimitotic activity. Proc Natl Acad Sci USA 1993; 90:96069610.

16 Keeshan K, He Y, Wouters BJ, et al. Tribbles homolog 2 inactivates $\mathrm{C} / \mathrm{EBP}[\mathrm{alpha}$ and causes acute myelogenous leukemia. Cancer Cell 2006; 10:401-411.

17 Calkhoven CF, Muller C, Leutz A. Translational control of $\mathrm{C} / \mathrm{EBPalpha}$ and $\mathrm{C} / \mathrm{EBP}$ beta isoform expression. Genes Dev 2000; 14:1920-1932.

18 Freytag SO, Paielli DL, Gilbert JD. Ectopic expression of the CCAAT/enhancer-binding protein alpha promotes the adipogenic program in a variety of mouse fibroblastic cells. Genes Dev 1994; 8:1654-1663.

19 Lin FT, Lane MD. Antisense CCAAT/enhancer-binding protein RNA suppresses coordinate gene expression and triglyceride accumulation during differentiation of 3T3-L1 preadipocytes. Genes Dev 1992; 6:533-544.

20 Wang ND, Finegold MJ, Bradley A, et al. Impaired energy homeostasis in C/EBP alpha knockout mice. Science 1995; 269:1108-1112.

21 Wang C, Chen L, Hou X, et al. Interactions between E2F1 and SirT1 regulate apoptotic response to DNA damage. Nat Cell Biol 2006; 8:1025-1031.

22 Qiang L, Wang H, Farmer SR. Adiponectin secretion is regulated by SIRT1 and the ER oxidoreductase Ero1-L $\{$ alpha\}. Mol Cell Biol 2007; 27:4698-4707.

23 Darlington GJ, Ross SE, MacDougald OA. The role of C/ EBP genes in adipocyte differentiation. J Biol Chem 1998; 273:30057-30060.

24 Nemoto S, Fergusson MM, Finkel T. Nutrient availability regulates SIRT1 through a forkhead-dependent pathway. Science 2004; 306:2105-2108.

25 Shin SM, Kim K, Kim JK, Yoon SR, Choi I, Yang Y. Dexamethasone reverses TGF-beta-mediated inhibition of primary rat preadipocyte differentiation. FEBS Lett 2003; 543:25-30.

26 MacDougald OA, Mandrup S. Adipogenesis: forces that tip the scales. Trends Endocrinol Metab 2002; 13:5-11.

27 Dixon TM, Daniel KW, Farmer SR, Collins S. CCAAT/ enhancer-binding protein alpha is required for transcription of the beta 3 -adrenergic receptor gene during adipogenesis. $J$ Biol Chem 2001; 276:722-728.

28 Tamori Y, Masugi J, Nishino N, Kasuga M. Role of peroxisome proliferator-activated receptor-gamma in maintenance of the characteristics of mature 3T3-L1 adipocytes. Diabetes 2002; 51:2045-2055.

$29 \mathrm{Wu} \mathrm{Z}$, Rosen ED, Brun R, et al. Cross-regulation of C/EBP alpha and PPAR gamma controls the transcriptional pathway of adipogenesis and insulin sensitivity. Mol Cell 1999; 3:151158.

30 Lehrke M, Lazar MA. The many faces of PPARgamma. Cell 2005; 123:993-999.

31 Wang C, Chen X, Wang Y, Gong J, Hu G. C/EBPalphap30 plays transcriptional regulatory roles distinct from C/EBPalphap42. Cell Res 2007; 17:374-383.

32 van Harmelen V, Skurk T, Hauner H. Primary culture and differentiation of human adipocyte precursor cells. Methods Mol Med 2005; 107:125-135.

33 Jin QH, Zhao B, Zhang XJ. Cytochrome c release and endoplasmic reticulum stress are involved in caspase-dependent apoptosis induced by G418. Cell Mol Life Sci 2004; 61:18161825.

34 Jin Q, Yan T, Ge X, Sun C, Shi X, Zhai Q. Cytoplasm-localized SIRT1 enhances apoptosis. J Cell Physiol 2007; 213:8897.

35 Wolf D, Rodova M, Miska EA, Calvet JP, Kouzarides T. Acetylation of beta-catenin by CREB-binding protein (CBP). J Biol Chem 2002; 277:25562-25567.

36 Zhou YL, Snead ML. Identification of CCAAT/enhancerbinding protein alpha as a transactivator of the mouse amelogenin gene. J Biol Chem 2000; 275:12273-12280.

37 Rubins NE, Friedman JR, Le PP, Zhang L, Brestelli J, Kaestner KH. Transcriptional networks in the liver: hepatocyte nuclear factor 6 function is largely independent of Foxa2. Mol Cell Biol 2005; 25:7069-7077. 